\title{
Extracellular Signal-Regulated Kinase-2 within the Ventral Tegmental Area Regulates Responses to Stress
}

\author{
Sergio D. Iñiguez, ${ }^{1}$ Vincent Vialou, ${ }^{2}$ Brandon L. Warren, ${ }^{1}$ Jun-Li Cao, ${ }^{3}$ Lyonna F. Alcantara, ${ }^{1}$ Lindsey C. Davis, ${ }^{1}$ \\ Zarko Manojlovic, ${ }^{1}$ Rachael L. Neve, ${ }^{4}$ Scott J. Russo, ${ }^{2}$ Ming-Hu Han, ${ }^{2,3}$ Eric J. Nestler, ${ }^{2}$ and Carlos A. Bolaños-Guzmán ${ }^{1}$ \\ ${ }^{1}$ Department of Psychology and Program in Neuroscience, Florida State University, Tallahassee, Florida 32306-4301, ${ }^{2}$ Fishberg Department of Neuroscience \\ and ${ }^{3}$ Department of Pharmacology and Systems Therapeutics, Mount Sinai School of Medicine, New York, New York 10029-6574, \\ and ${ }^{4}$ Massachusetts Institute of Technology, Cambridge, Massachusetts 02139-4307
}

Neurotrophic factors and their signaling pathways have been implicated in the neurobiological adaptations in response to stress and the regulation of mood-related behaviors. A candidate signaling molecule implicated in mediating these cellular responses is the extracellular signal-regulated kinase (ERK1/2), although its functional role in mood regulation remains to be fully elucidated. Here we show that acute $(1 \mathrm{~d})$ or chronic ( 4 weeks) exposure to unpredictable stress increases phosphorylation of ERK1/2 and of two downstream targets (ribosomal S6 kinase and mitogen- and stress-activated protein kinase 1) within the ventral tegmental area (VTA), an important substrate for motivated behavior and mood regulation. Using herpes simplex virus-mediated gene transfer to assess the functional significance of this ERK induction, we show that overexpressing ERK2 within the VTA increases susceptibility to stress as measured in the forced swim test, responses to unconditioned nociceptive stimuli, and elevated plus maze in Sprague Dawley male rats, and in the tail suspension test and chronic social defeat stress procedure in C57BL/6 male mice. In contrast, blocking ERK2 activity in the VTA produces stress-resistant behavioral responses in these same assays and also blocks a chronic stress-induced reduction in sucrose preference. The effects induced by ERK2 blockade were accompanied by decreases in the firing frequency of VTA dopamine neurons, an important electrophysiological hallmark of resilient-like behavior. Together, these results strongly implicate a role for ERK2 signaling in the VTA as a key modulator of responsiveness to stress and mood-related behaviors.

\section{Introduction}

Acting in several brain regions, neurotrophins and their signaling pathways play significant roles in neuronal excitability, synaptic transmission, models of learning and memory (Schuman, 1999; Poo, 2001; Alonso et al., 2002; Rattiner et al., 2005), and responses to drugs of abuse (Horger et al., 1999; Pierce and Bari, 2001; Bolaños and Nestler, 2004; Lu et al., 2004; Russo et al., 2007; Schoenbaum et al., 2007; Graham et al., 2009). Neurotrophin signaling cascades have also been shown to play crucial roles in regulating responses to stress in several animal models of depression and antidepressant action (Russo-Neustadt et al., 2000; Nestler et al., 2002; Eisch et al., 2003; Rattiner et al., 2005; Berton et al., 2006; Duman and Monteggia, 2006; Schmidt and Duman, 2007).

Midbrain dopamine neurons of the ventral tegmental area (VTA) and their projections to the nucleus accumbens (NAc), which together form the mesolimbic dopamine system, express neurotrophins and their Trk receptors (Conner et al., 1997; Yan

Received Feb. 22, 2010; revised April 9, 2010; accepted April 15, 2010.

This work was supported by grants from the National Institute on Drug Abuse (C.A.B.-G., E.J.N.) and the National Institute of Mental Health (E.J.N.). S.D.I. was supported by a McKnight Fellowship from the Florida Education Fund a Neuroscience Fellowship from Florida State University, and National Institute on Drug Abuse National Research Service Award F31DA027300. B.L.W. was supported by a Neuroscience Fellowship from Florida State University.

Correspondence should be addressed to Dr. Carlos A. Bolaños-Guzmán, Department of Psychology, 1107 West Call Street, Florida State University, Tallahassee, FL 32306. E-mail: bolanos@psy.fsu.edu.

D01:10.1523/JNEUROSCI.0951-10.2010

Copyright $\odot 2010$ the authors $\quad 0270-6474 / 10 / 307652-12 \$ 15.00 / 0$ et al., 1997; Numan and Seroogy, 1999). The VTA-NAc pathway is best known for its role in encoding the incentive-motivational valence of drug and natural rewards (Koob and Le Moal, 2001; Kelley and Berridge, 2002; Wise, 2004). Chronic exposure to drugs of abuse has been shown to alter neurotrophin signaling cascades within the VTA, including upregulation of the extracellular signal-regulated kinase (ERK) cascade (Ortiz et al., 1995; Berhow et al., 1996; Nestler et al., 1996; Russo et al., 2007). ERK consists of two isoforms (ERK1 and ERK2) and is one of several mitogen-activated protein kinases involved in numerous cellular processes, including long-term neuronal plasticity, maintenance, and survival (Hetman and Gozdz, 2004; Subramaniam and Unsicker, 2010). More recently, ERK has also been implicated in adaptive responses to stress and antidepressant treatments, although in brain regions other than the VTA-NAc circuitry (Einat et al., 2003; Dwivedi et al., 2006; Duman et al., 2007; Gourley et al., 2008).

Beyond addiction, the mesolimbic dopamine system has been increasingly implicated in the regulation of mood- and depression-related behaviors (Fibiger and Phillips, 1981; Willner, 1983; Anisman and Zacharko, 1986; Wise, 1987; Koob, 1996; Naranjo et al., 2001; Nestler and Carlezon, 2006). Chronic exposure to stress activates the VTA-NAc pathway (BertolucciD’Angio et al., 1990; Horger and Roth, 1996; Jensen et al., 2003). Moreover, previous exposure to stress sensitizes an individual to the effects of drugs of abuse and vice versa (Shaham et al., 2000; Covington and Miczek, 2005), and chronic stress causes many of 
the same long-term molecular and cellular adaptations seen after acute or chronic administration of drugs of abuse (Fitzgerald et al., 1996; Ortiz et al., 1996; Saal et al., 2003; Krishnan et al., 2007). Based on these shared actions of drugs of abuse and stress, the goal of the present investigation was to assess whether acute or chronic stress, such as drugs of abuse, alters the ERK pathway within the VTA and, if so, whether such adaptations can influence an animal's functional responses to stress and other moodrelated stimuli.

\section{Materials and Methods}

Animals. For all experiments, animals were male, fed ad libitum, allowed a 1 week habituation period before experimental manipulation, and housed at $23-25^{\circ} \mathrm{C}$ on a $12 \mathrm{~h}$ light/dark cycle (lights on at 7:00 A.M.). Sprague Dawley rats (275-300 g; Charles River), 9-week-old C57BL/6 mice (The Jackson Laboratory), and CD1 retired breeders (Charles River) were used in this study. Rats (two per cage) and C57BL/6 (four per cage) and CD1 (one per cage) mice were housed in clear polypropylene boxes containing wood shavings. Experiments were conducted in compliance with the guidelines for the Care and Use of Laboratory Animals (Council, 2003) and approved by the Florida State University Animal Care and Use Committee.

Acute and chronic unpredictable stress. An initial experiment was performed to assess how stress affects ERK phosphorylation within the VTA. More specifically, rats were randomly assigned to either an acute or chronic unpredictable stress regimen. Rats in the acute condition were stressed one time only: forced to swim for 15 min under conditions they could not escape $\left(18^{\circ} \mathrm{C}\right.$ water; light cycle). Under chronic stress, rats were subjected to single daily episodes of unpredictable stress for 4 weeks (Willner et al., 1987; Perrotti et al., 2004). Chronic stress consisted of randomized periods of food or water deprivation (overnight), continuous cage shaking ( $1 \mathrm{~h}$ on an automatic shaker; light cycle), forced swim stress ( $15 \mathrm{~min}$, in $18^{\circ} \mathrm{C}$ water; light cycle), continuous overnight illumination ( $12 \mathrm{~h}$ ), intermittent illumination ( $12 \mathrm{~h} ; 2 / 2 \mathrm{~h}$ light/dark), overcrowded caging ( 10 rats per cage; overnight), wet cage ( $12 \mathrm{~h}$; light cycle), exposure to cold temperature $\left(1 \mathrm{~h}\right.$ at $4^{\circ} \mathrm{C}$; light cycle $)$, and acute restraint stress (40 min; light cycle) using plastic DecapiCones (Briantree Scientific). Immediately after the last episode of stress (i.e., forced swimming in the acute stress condition or physical restraint in the chronic stress condition) VTA punches were collected and maintained at $-80^{\circ} \mathrm{C}$ until immunoassayed.

Western blotting. Tissue punches of VTA (1.25 mm diameter) from rats were sonicated in a standard lysis buffer and then centrifuged at $14,000 \mathrm{rpm}$ for $15 \mathrm{~min}$. Samples ( $20 \mu \mathrm{g}$; estimated through the Bradford assay) were treated with $\beta$-mercaptoethanol and subsequently electrophoresed on precast $4-20 \%$ gradient gels (Bio-Rad). Proteins were transferred to a polyvinylidene fluoride membrane, washed in $1 \times$ Tris-buffered saline with $0.1 \%$ Tween 20 (TBST), and blocked in milk dissolved in TBST (5\% $\mathrm{w} / \mathrm{v}$ ) for $1 \mathrm{~h}$ at $25^{\circ} \mathrm{C}$. Blots were probed (overnight at $4^{\circ} \mathrm{C}$ ) with antibodies against the phosphorylated forms of the protein [except tyrosine hydroxylase (TH) and glyceraldehyde-3-phosphate dehydrogenase (GAPDH)] and then stripped (Restore; Thermo Fisher Scientific) and probed with antibodies against total protein of the same type. Antibodies were from Cell Signaling Technology [ERK1/2, ribosomal S6 kinase of $90 \mathrm{kDa}$ (90RSK), and mitogen- and stress-activated protein kinase 1 (MSK1), phospho (p)-protein and total (t) protein, except total MSK1)] and were used according to the instructions of the manufacturer (in 5\% milk dissolved in TBST). After additional washes, membranes were incubated with peroxidase-labeled goat anti-rabbit IgG or horse anti-mouse IgG (1:40,000; Vector Laboratories). Bands were visualized with SuperSignal West Dura substrate (Pierce Biotechnology) and quantified (normalized to GAPDH) using NIH ImageJ.

Viral manipulation, behavioral design, and procedures. Based on the results from the acute and chronic stress experiment described above, separate groups of rats were microinjected with herpes simplex virus (HSV) vectors encoding green fluorescent protein (GFP), wild-type ERK2-GFP (wtERK2), or a dominant-negative mutant of ERK2-GFP (dnERK2) to determine whether direct viral-mediated gene manipula- tion modulates ERK signaling and, if so, assess whether the viral-induced adaptations influence the firing rate of dopamine neurons within the VTA. After these experiments, separate groups of rats and C57BL/6 mice received microinfusions of HSV-GFP, HSV-wtERK2, or HSV-dnERK2 within the VTA to further assess how manipulation of ERK2 itself influences an animal's reactivity to stress. Thus, subjects were tested on different behavioral procedures designed to assess functional responses to stressful situations and other emotion-eliciting stimuli. All viralmediated experiments were performed $3 \mathrm{~d}$ after virus infusion as described below.

Viral vectors. The construction of the HSV vectors has been described previously (Robinson et al., 1996; Neve et al., 1997), and the ERK2 vectors have been validated in vivo and in vitro (Krishnan et al., 2007; Russo et al., 2007; present results). The average titer of the recombinant virus stocks was $4.0 \times 10^{7}$ infectious units $/ \mathrm{ml}$. Titers did not differ by $>10 \%$ among preparations. All behavioral experiments were commenced on day 3 after viral surgery, a time at which maximal transgene expression caused by these vectors is observed (Carlezon et al., 1998; Barrot et al., 2002). Expression of the HSV-encoded transgenes was limited to an area of $\sim 1 \mathrm{~mm}^{3}$ around the injection site, and viral expression was not apparent in either afferent or efferent regions of the injected area. Thus, we found no detectable HSV expression in either the NAc or the dorsal raphe (Bolaños et al., 2003b; Iñiguez et al., 2008).

Animal surgery. For stereotaxic delivery of the viruses, rats were anesthetized with a ketamine/xylazine mixture $(80 / 10 \mathrm{mg} / \mathrm{kg}$, i.m.) and given atropine $(0.25 \mathrm{mg} / \mathrm{kg}$, s.c.) to minimize bronchial secretions; afterward, rats were given bilateral microinjections $(1.0 \mu \mathrm{l}$ per side over $10 \mathrm{~min}$ of HSV-GFP, HSV-wtERK2, or HSV-dnERK2) into the rostral region of the VTA [anteroposterior, $-4.9 \mathrm{~mm}$; lateral, $+2.2 \mathrm{~mm}$; dorsoventral, $-7.6 \mathrm{~mm}$ below dura (Paxinos and Watson, 1997)], using a 32 gauge Hamilton syringe angled at $10^{\circ}$ from the midline, to avoid piercing the sinus system. Similarly, mice were anesthetized with ketamine/xylazine $(100 / 10 \mathrm{mg} / \mathrm{kg}$, i.p. $)$ and received bilateral infusions $(0.5 \mu \mathrm{l}$ over $5 \mathrm{~min})$ of virus into established mouse VTA coordinates (anteroposterior, -3.2 $\mathrm{mm}$; lateral, $+1.0 \mathrm{~mm}$; dorsoventral, $-4.6 \mathrm{~mm} ; 7^{\circ}$ angle). The VTA injection sites were confirmed in all animals by standard histology methods (described below). The local anesthetic bupivacaine was applied directly along the wound edges to minimize any potential postoperative discomfort.

Histology and transgene detection. At the end of the behavioral experiments, rats and mice were given an overdose of pentobarbital and perfused transcardially with $0.9 \%$ saline, followed by cold $4 \%$ paraformaldehyde. The brains were removed, postfixed overnight in $4 \%$ paraformaldehyde, and stored in 20\% glycerol solution. Coronal sections ( 45 $\mu \mathrm{m})$ through the midbrain were taken on a microtome and stored in $0.1 \mathrm{M}$ sodium phosphate buffer with $0.05 \%$ azide. Sections were processed to examine the ability of HSV construct to drive expression of GFP and TH within the VTA as described previously (Russo et al., 2007). Midbrain free-floating coronal sections were processed for immunohistochemistry using the following antibodies: rabbit anti-GFP (1:1000; Abcam) and TH (mouse; 1:5000; Millipore Bioscience Research Reagents), a marker of VTA dopamine neurons. Adjacent sections were blocked in 3\% normal donkey serum (NDS) and incubated overnight in one of the primary antibodies mentioned above, along with $0.3 \%$ Triton X-100 (Thermo Fisher Scientific) and 1\% NDS. Sections were incubated with anti-rabbit or anti-mouse secondary antibody (Jackson ImmunoResearch) for $2 \mathrm{~h}$ at room temperature. Stained sections were then slide mounted (Thermo Fisher Scientific), dehydrated in ethanol and citrosolv, and coverslipped with clear DPX adhesive (Sigma). Slides were then visualized and photographed using a fluorescence microscope and a digital camera. Data obtained from animals with placements outside the intended brain regions $(<10 \%$ of all experimental animals) were not included in the analyses.

Forced swimming and tail suspension tests. The forced swim test is a $2 \mathrm{~d}$ procedure in which rats are forced to swim under conditions in which they cannot escape. On the first day, rats are forced to swim. Initially, they engage in escape-like behaviors but eventually adopt a posture of immobility in which they make only the movements necessary to maintain their head above water. When retested $24 \mathrm{~h}$ later, rats become immobile 
very quickly; however, antidepressant treatment between the forced swim exposures can significantly increase their escape-like behaviors, an effect that has been correlated with antidepressant activity in humans (Steru et al., 1985; Porsolt et al., 1987; Cryan et al., 2005). At the start of the experiment, rats received intra-VTA injections of HSV-GFP, HSVwtERK2, or HSV-dnERK2 and were left undisturbed to recover for $2 \mathrm{~d}$. Twenty-four hours later ( $3 \mathrm{~d}$ after viral infusion), rats were placed in plastic cylinders $(75 \times 30 \mathrm{~cm})$ filled to $54 \mathrm{~cm}$ depth with $25^{\circ} \mathrm{C}$ water and forced to swim for $15 \mathrm{~min}$. At the end of this period, rats were removed from the water, dried with towels, placed in a warmed enclosure for 30 $\mathrm{min}$, and then returned to their home cage. All cylinders were emptied and cleaned between rats. Twenty-four hours later, rats were retested for 5 min under identical conditions, and sessions were videotaped. In this study, the latency to become immobile, total immobility, and behavioral counts (i.e., floating, climbing, and swimming) were the dependent variables. Latency to immobility was defined as the time at which the rat first initiated a stationary posture that did not reflect attempts to escape from the water. To qualify as immobility, this posture had to be clearly visible and maintained for $\geq 2.0 \mathrm{~s}$. Behavioral counts were taken at $5 \mathrm{~s}$ intervals during the 5 min retest (Detke and Lucki, 1996; Lucki, 1997; Pliakas et al., 2001).

A related test of behavioral despair, the tail suspension test, was performed in C57BL/6 mice. This test involves the stress of being suspended by the tail in a manner in which they cannot escape rather than forced to swim (Steru et al., 1985; Cryan et al., 2005). Mice were microinjected with HSV vectors into the VTA and, 3 d later, were suspended by their tail for $5 \mathrm{~min}$, and the total time spent immobile (seconds) was measured.

Basal locomotor activity after day 1 of forced swimming. Spontaneous locomotor activity was indexed as distance traveled (centimeters) in an open field $(63 \times 63 \mathrm{~cm})$ that consisted of a square box that rats can explore freely (Wiley et al., 2009; Iñiguez et al., 2010). This task was performed $24 \mathrm{~h}$ after the forced swim test on day 1 to assess whether the effects observed in the forced swim test (day 2) could be confounded by changes in general locomotor activity after viral-mediated gene transfer.

Social defeat stress. To further delineate how ERK2 modulation within the VTA influences responsiveness to stressful situations, we conducted social defeat experiments in C57BL/6 male mice. CD1 mice with consistent attack latencies ( $\leq 30 \mathrm{~s}$ on three consecutive screening tests) were housed in cages fitted with perforated Plexiglas separators (Florida State University Psychology, Engineering Group), which allow sensory contact without permitting physical contact, and used to defeat C57BL/6 mice in two separate experiments (Berton et al., 2006; Krishnan et al., 2007). In the first experiment, naive mice were microinjected with HSV-GFP or HSV-wtERK2 and were exposed to a submaximal defeat protocol: three 5-min-long defeat episodes interspersed by 15 min rest periods (see Fig. $4 a$ ) on a single day (Krishnan et al., 2008). Social avoidance behaviors toward an unfamiliar CD1 mouse were assessed the following day in a two-stage social interaction test. In the first $2.5 \mathrm{~min}$ trial ("target absent"), the experimental C57BL/6 mouse was allowed to freely explore a square-shaped open-field arena $(44 \times 44 \mathrm{~cm})$ containing a wire-mesh cage $(10 \times 6 \mathrm{~cm})$ apposed to one side (see Fig. $4 b)$. During the second 2.5 min trial ("target present"), the mouse was reintroduced into this arena now containing an unfamiliar CD1 mouse within the cage. Videotracking software (Noldus) was used to measure the time spent in the "interaction zone" $(14 \times 26 \mathrm{~cm})$ and the "corner zones" $(10 \times 10 \mathrm{~cm})$. For the second experiment (see Fig. $4 c$ ), a separate group of naive mice were defeated for $10 \mathrm{~d}(10 \mathrm{~min} / \mathrm{d})$. After the social interaction test (day 11), the defeated mice (those showing social avoidance) were randomly assigned to receive HSV-GFP or HSV-dnERK2 vectors into the VTA. Three days after surgery, avoidance behaviors (social interaction test) toward an unfamiliar CD1 mouse were assessed (Krishnan et al., 2007, 2008).

Sucrose preference. Two separate sucrose preference tests were conducted using a two-bottle choice procedure under red light at the beginning of the dark phase. In the first experiment, rats were habituated to drink a $1 \%$ sucrose solution for $3 \mathrm{~d}$ (from two drip-controlled bottles). On day 4, the sucrose solution was replaced with tap water for an additional 2 d. Two hours (5:00 P.M.) before the test (at the end of day 5), rats were singly housed with access to food. At the start of the dark phase (7:00
P.M.), rats were given access to the two bottles (containing water or $1 \%$ sucrose). The position of the water and sucrose bottles (left or right) was switched every $30 \mathrm{~min}$ from 7:00 P.M. to 10:00 P.M. After the $3 \mathrm{~h}$ period, rats were left undisturbed, and their overnight fluid consumption was measured the next morning (8:00 A.M.). The preference for sucrose over water [i.e., sucrose/(water + sucrose)] was used as a measure for rats sensitivity to reward (Willner et al., 1987; Iñiguez et al., 2009). No differences in sucrose preference or liquid intake were found during the $3 \mathrm{~h}$ period; thus the water and sucrose consumption data analyzed were those taken at 7:00 P.M. and 8:00 A.M. At the end of the testing period, rats were again housed in pairs. The total amount of fluid (water or sucrose) intake was considered baseline preference. Only rats showing a $\leq 60 \%$ preference to sucrose over water were used for the rest of the experiment. Four days after the pretest (i.e., baseline preference), animals received intracranial HSV microinjections into the VTA. On day 3 after surgery, the sucrose preference test was repeated exactly as performed on day 5 of baseline (Barrot et al., 2002; Bolaños et al., 2003b). The second experiment was conducted to assess whether ERK2 could influence preference for sucrose after chronic unpredictable stress. After baseline preferences (procedure as described above), rats were exposed to $7 \mathrm{~d}$ of chronic unpredictable stress as described above (Willner et al., 1987; Perrotti et al., 2004). Twenty-four hours after the last day of stress (forced swimming), animals received intracranial HSV or sham microinjections into the VTA. On day 3 after surgery, the sucrose preference test was performed (as described above).

Responses to nociceptive stimuli. In this test, rats were exposed to an electric footshock session in an apparatus consisting of a computerized box with a grid $3 \mathrm{~d}$ after viral infusions into the VTA (Barrot et al., 2002; Bolaños et al., 2003b). The threshold of footshock intensity required to induce a behavioral response was determined. After $2 \mathrm{~min}$ of habituation to the testing chamber, rats received a footshock every $30 \mathrm{~s}$ starting at 0.05 $\mathrm{mA}$, with a $0.05 \mathrm{~mA}$ increment between each shock (to a maximum of 1.0 $\mathrm{mA}$ ). The intensity at which a flinch, an audible vocalization, or a jump first appeared was recorded. The test session was terminated after all three behavioral responses were observed in each animal (Bonnet and Peterson, 1975; Barrot et al., 2002; Bolaños et al., 2003b).

Elevated plus maze. Rats receiving HSV microinjections into the VTA were tested for $5 \mathrm{~min}$ on the elevated plus maze, a test of anxiety-like behavior (Montgomery, 1955). The maze was made of gray plastic and consisted of two perpendicular, intersecting runways $(12 \mathrm{~cm}$ wide $\times 100$ cm long). One runway had tall walls (40 cm high) or "closed arms," and the other one had no walls or "open arms." The arms were connected together by a central area, and the maze was elevated $1 \mathrm{~m}$ from the floor. At the beginning of the test, under controlled light conditions ( $~ 90$ lux), rats were placed in the central area, facing one of the open arms, and the cumulative time spent in the open arms was videotaped. We also assessed self-grooming in the closed arms because rats engage in repetitive grooming in response to anxiogenic stimuli (Spruijt et al., 1988; Bolaños et al., 2003a).

VTA slice cultures. Slice cultures were prepared as described previously (Han et al., 2006; Krishnan et al., 2007, 2008). Acute coronal brain slices $(300 \mu \mathrm{m})$ containing the VTA were obtained in sucrose-artificial CSF (aCSF) (for composition, see below, Electrophysiology). Slices were trimmed as small as possible and were maintained for up to $3 \mathrm{~d}$ in $34^{\circ} \mathrm{C}$ incubator. We used Invitrogen MEM containing $30 \mathrm{~mm}$ HEPES, $20 \mathrm{~mm}$ D-glucose, 5\% B27, $5.0 \mathrm{~mm}$ L-glutamine, and $25 \mathrm{U} / \mathrm{ml}$ streptomycin/ penicillin. This culture medium successfully maintained stable pacemaker activity of the dopamine neurons in the VTA slice cultures.

Electrophysiology. Brain was quickly removed and put into cold sucroseaCSF, which was derived by fully replacing $\mathrm{NaCl}$ with $254 \mathrm{~mm}$ sucrose in aCSF; it contained the following (in $\mathrm{mM}$ ): $128 \mathrm{NaCl}, 3 \mathrm{KCl}, 1.25$ $\mathrm{NaH}_{2} \mathrm{PO}_{4}, 10$ D-glucose, $24 \mathrm{NaHCO}_{3}, 2 \mathrm{CaCl}_{2}$, and $2 \mathrm{MgCl}_{2}$ (oxygenated with $95 \% \mathrm{O}_{2}$ and $5 \% \mathrm{CO}_{2}$, pH 7.35, 295-305 mOsm). Brain slices containing VTA were cut using a microslicer (DTK-1000; Ted Pella) in cold sucrose-aCSF. Slices were kept for recovery in a holding chamber with aCSF for $1 \mathrm{~h}$ at $37^{\circ} \mathrm{C}$, and HSV vectors were pipetted onto the VTA area of the slice surface. VTA slice cultures were transferred into a recording chamber, in which a constant flow of aCSF $(\sim 2.5 \mathrm{ml} / \mathrm{min})$ was maintained throughout the experiment at $34^{\circ} \mathrm{C}$. Single-unit extracellular po- 
tentials were recorded by the use of loose patch recording mode (Han et al., 2006; Krishnan et al., 2007, 2008) with glass pipettes filled with 115 $\mathrm{mm}$ potassium gluconate, $20 \mathrm{mM} \mathrm{KCl}, 1.5 \mathrm{~mm} \mathrm{MgCl}_{2}, 10 \mathrm{~mm}$ phosphocreatine, 10 mm HEPES, 2 mm ATP-Mg, and $0.5 \mathrm{~mm}$ GTP, pH 7.2, 285 $\mathrm{mOsm}$, and monitored through high-input impedance amplifier (axoclamp 2B; Molecular Devices). VTA dopamine neurons in these experiments were identified by location and well established electrophysiological criteria: regular spontaneous firing, action potential (AP) with triphasic waveforms (positive, negative, positive), and AP width (from start to trough) $>1.1 \mathrm{~ms}$ under the filter conditions of $300 \mathrm{~Hz}$ to $0.8 \mathrm{kHz}$ as reported previously (Ungless et al., 2004; Werkman et al., 2004; Krishnan et al., 2008). The waveform of AP (see Fig. 7a) for measuring AP width was obtained by averaging 30-40 AP episodes. The firing rate of dopamine neurons were recorded in the bridge mode of amplifier AxoClamp 2B, and data acquisition and online analysis of firing rate were realized with Digidata 1322A digitizer and pClamp 8.2 (Molecular Devices).

Statistical analyses. Assignment of subjects to the various testing and viral conditions was random. Behavioral data were analyzed using oneor two-way ANOVA, followed by Tukey's post hoc test. A $t$ test was used for all other analyses implicating only a two-groups comparison. Data are expressed as the mean \pm SEM. In all cases, statistical significance was defined as $p<0.05$.

\section{Results}

\section{Stress increases ERK signaling within the VTA}

Immunoblot analysis was used to examine the effects of acute or chronic unpredictable stress on ERK activity, as inferred from the phosphorylation of ERK1/2 and of two downstream targets, 90RSK and MSK1, within the VTA. Figure 1 shows immunoblots of VTA homogenates representing averages of expression levels of pERK1, pERK2, p90RSK, pMSK1, and tTH under acute $(a)$ and chronic $(b)$ stress conditions. Acute stress $(n=10$ per group) significantly increased levels of pERK1 $\left(t_{(18)}=2.89, p<0.001\right)$, pERK2 $\left(t_{(18)}=4.71, p<0.0002\right)$, p90RSK $\left(t_{(18)}=4.49, p<\right.$ $0.0003)$, and pMSK1 $\left(t_{(18)}=6.63, p<0.0001\right)$, with no changes in tERK1, tERK2, t90RSK, and tTH ( $p>0.05$, respectively) when compared with controls (all normalized to GAPDH). Chronic unpredictable stress ( $n=5$ per group) similarly increased levels of pERK1 $\left(t_{(8)}=2.03, p<0.04\right)$, pERK2 $\left(t_{(8)}=2.11, p<0.03\right)$, p90RSK $\left(t_{(8)}=2.05, p<0.03\right)$, and pMSK1 $\left(t_{(8)}=3.72, p<\right.$ $0.01)$, with no changes in total levels of these enzymes, including $\mathrm{TH}(p>0.05$, respectively), when compared with controls.

\section{Validation of viral-mediated gene transfer in the VTA}

Figure $2 a$ shows the region of the VTA to which microinjections of HSV vectors (HSV-GFP, HSV-wtERK2, or HSV-dnERK2) were targeted. As reported previously, we found that virus expression was maximal between days 3 and 4 after injection (data not shown), significantly declining thereafter, and nondetectable 1 week after the microinjection (Carlezon et al., 1997; Barrot et al., 2002; Olson et al., 2005). Confocal microscopy (Fig. 2b-d) revealed that the percentage of TH-positive neurons overexpressing GFP in the VTA ( 53\%) was similar to previous findings (Olson et al., 2005; Russo et al., 2007) with no detectable expression of the viral-encoded transgenes in glial cells (data not shown).

We also demonstrated that our viral-mediated gene transfer manipulation modulates ERK signaling in the VTA. Three days after viral microinjections, VTA punches were obtained from infected rats ( $n=6$ per group) for immunoblotting studies in which we examined a panel of antibodies against molecules involved in ERK signaling (Fig. 2e). Separate one-way ANOVAs (for protein of interest) showed significant differences in pERK2 $\left(F_{(2,15)}=6.31, p<0.01\right)$ and other pERK-dependent signaling
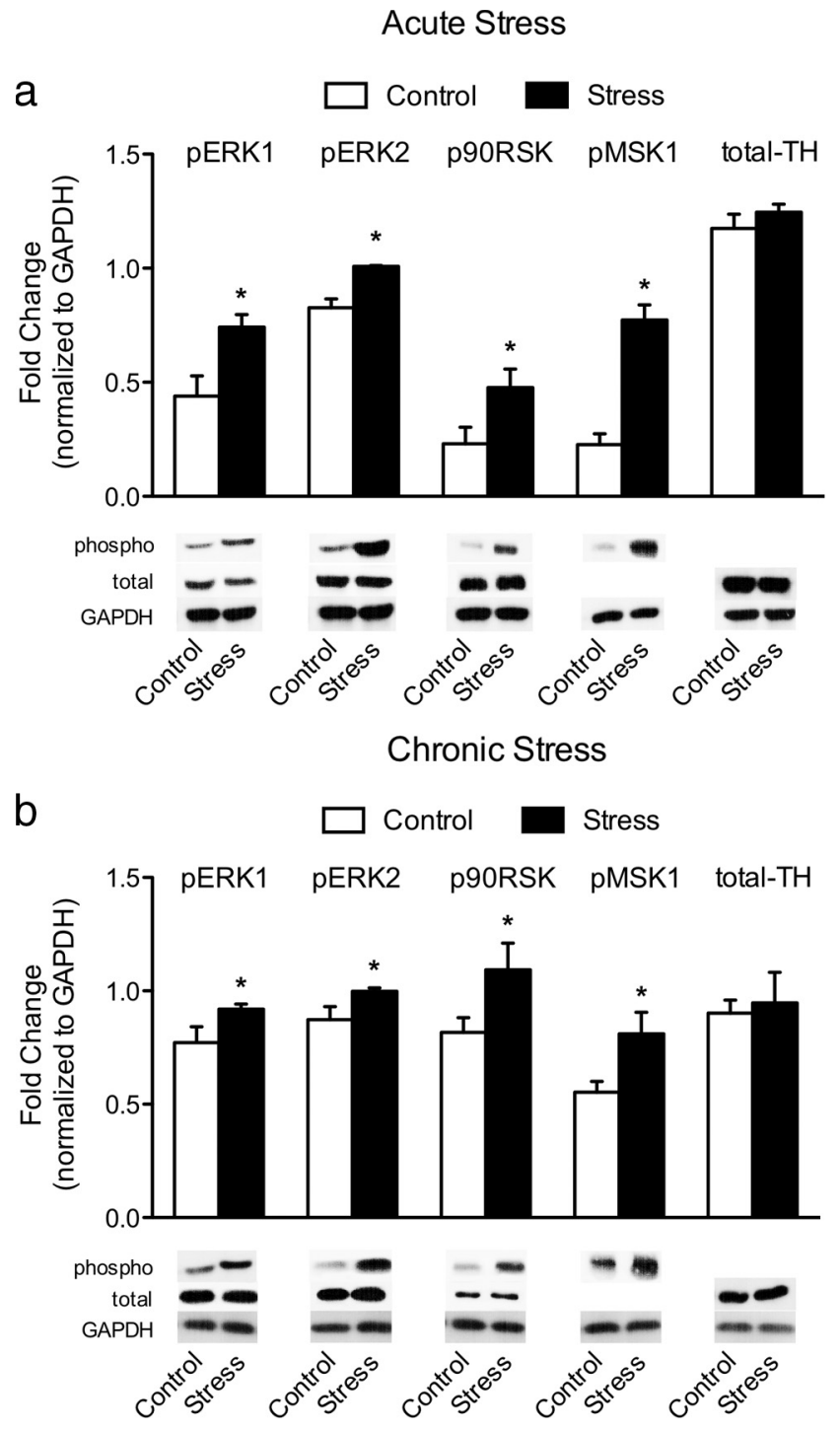

Figure 1. $\quad \boldsymbol{a}, \boldsymbol{b}$, Immunoblots of rat VTA homogenates representing average expression levels of pERK1, pERK2, p90RSK, pMSK1, and tTH under acute $(\boldsymbol{a})$ and chronic unpredictable $(\boldsymbol{b})$ stress conditions. Acute stress ( $n=10$ per group) consisted of a single exposure to forced swimming (15 min). Chronic stress ( $n=5$ per group) consisted of daily episodes of stress for 4 weeks, ending with physical restraint ( $40 \mathrm{~min}$ ). Tissue was extracted immediately after the last exposure to stress. Both acute and chronic stress significantly increased the levels of pERK1, pERK2, p9ORSK, and pMSK1 (normalized to GAPDH) without affecting total levels of these proteins, or total TH when compared with controls. Data are shown as mean \pm SEM. ${ }^{*} p<0.05$ compared with respective controls.

proteins as a function of virus treatment (p90RSK, $F_{(2,15)}=5.71$, $p<0.01$; pMSK1, $F_{(2,15)}=28.77, p<0.0001$, respectively). Post hoc analyses showed that HSV-wtERK2 significantly increased pERK2, p90RSK, and pMSK1 levels, whereas HSV-dnERK2 significantly decreased pERK2, p90RSK, and pMSK1 levels $(p<$ 0.05 , respectively) compared with their respective HSV-GFP controls. Conversely, no differences in levels of pERK1 as a function of virus were detected ( $p>0.05)$. Similarly, no differences in tERK1, tERK2, t90RSK, or tTH as a function of virus treatment were observed $(p>0.05)$.

ERK2 regulation of behavioral responses to emotion-eliciting stimuli

Based on the ability of acute and chronic unpredictable stress to increase ERK2 signaling in the VTA, it was of interest to study the 
functional consequences of altered ERK activity in this brain region on emotional behavior. Increased ERK2 function was induced in the VTA of adult rats or mice by local injection of HSV-wtERK2, whereas decreased ERK2 function was induced by HSV-dnERK2 injection.

ERK2 activity in the VTA regulates behavioral reactivity to forced swimming and tail suspension stress

We first used the forced swim test in rats, which is used widely as a screen for antidepressant efficacy as well as a measure of behavioral despair (Pliakas et al., 2001; Cryan et al., 2002). In this test, animals initially struggle in an attempt to escape but within 1-2 min become immobile. The effects of HSV-GFP, HSV-wtERK2, and HSV-dnERK2 on day 2 of forced swimming are shown in Figure $3, a$ and $b$ ( $n=12-13$ per group). We found that the amount of time rats engaged in escapedirected behaviors in the forced swim test was dependent on viral treatment. Latency to become immobile varied as a function of virus treatment $\left(F_{(2,34)}=42.04, p<\right.$ 0.0001) (Fig. 3a). HSV-wtERK2-treated rats had shorter latencies to become immobile (interpreted as increased susceptibility to stress) when compared with HSV-GFP-treated rats $(p<0.05)$. Conversely, HSV-dnERK2-treated rats displayed significantly longer latencies to become immobile (decreased susceptibility to stress) when compared with HSVGFP-treated controls $(p<0.05)$. Virus treatments also influenced total immobility $\left(F_{(2,34)}=8.81, p<0.001\right)$, with HSV-dnERK2-treated rats showing significantly lower total immobility when compared with the HSV-GFP-treated group ( $p<0.05)$. This dnERK2-induced stress-resistant phenotype was correlated with lower floating counts $\left(F_{(2,34)}=7.16, p<0.003\right)$ and higher climbing counts $\left(F_{(2,34)}=9.25, p<0.001\right)$ and a tendency for higher swimming counts $(p=0.07)$ when compared with controls (Fig. $3 b)$. In contrast to the VTA, HSV microinjections into the substantia nigra ( $n=5$ per group) did not alter the responses $(p>0.05)$ of the animals in the forced swim test (Fig. 3c).

A separate group of rats receiving HSV-wtERK2, HSVdnERK2, or HSV-GFP into the VTA ( $n=4$ per group) were tested in the open-field box to assess whether the effects observed in the forced swim test could be confounded by changes in general locomotor activity after viral-mediated gene transfer. As can be seen in the inset of Figure $3 b$, no significant differences were apparent between the groups when locomotor activity was assessed $24 \mathrm{~h}$ after day 1 of forced swimming.

To complement the findings from the forced swim test in a second species, we studied the effect of viral infusions into the VTA of C57BL/6 mice in the tail suspension test $(n=6$ per group), in which total immobility has been widely validated as a measure of antidepressant efficacy and depression-like behavior (Cryan et al., 2005). We obtained results very similar to those observed in the forced swim test with rats $\left(F_{(2,15)}=16.59, p<\right.$
0.0002) (Fig. 3d). HSV-wtERK2-treated mice showed higher total immobility ( $p<0.05$; increased susceptibility to stress), whereas HSV-dnERK2-treated mice showed lower total immobility ( $p<0.05$; decreased susceptibility to stress) when compared with the HSV-GFP controls.

\section{ERK2 activity in the VTA regulates vulnerability to social defeat stress}

To further assess the causal role of ERK2 activity in the VTA as a mediator of increased vulnerability to stress, we microinjected HSV-GFP $(n=6)$ or HSV-wtERK2 $(n=8)$ into the VTA of naive $\mathrm{C} 57 \mathrm{BL} / 6$ mice and assessed their social interaction time after a submaximal period of social defeat (Fig. 4a). This behavioral assay has been used previously to study molecular adaptations that promote stress vulnerability (Krishnan et al., 2007, 2008). As can be seen in Figure 4d, HSV-GFP-treated mice demonstrated significantly higher levels of social interaction when the target is present (target absent vs present, $t_{(10)}=2.75, p<0.02$ ), similar to responses observed in uninjected control mice (data not shown). In contrast, no change in social interaction was observed in the HSV-wtERK2-treated mice during exposure to a social target (target absent vs present, $p>0.05$ ). These results indicate that the submaximal social defeat protocol used was, as expected, not sufficient to induce social avoidance in the HSVGFP mice but did induce significant social avoidance in HSVwtERK2-treated mice when compared with controls (target 
a

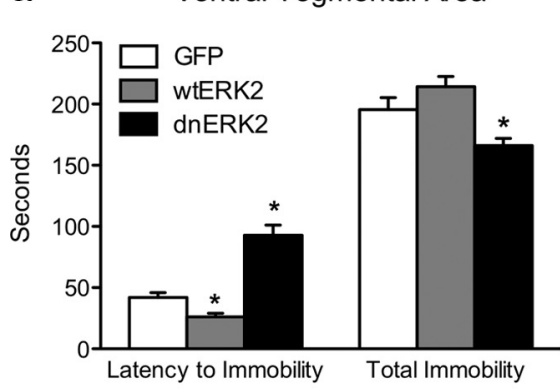

b

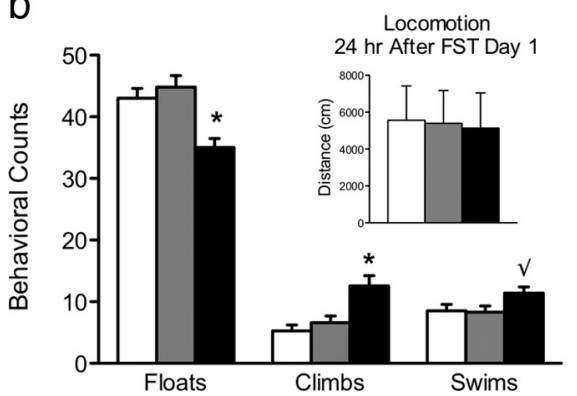

C

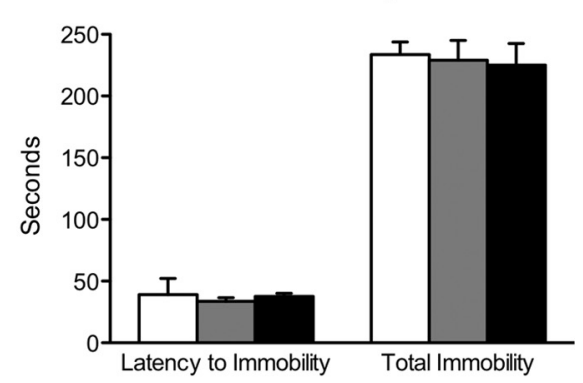

d

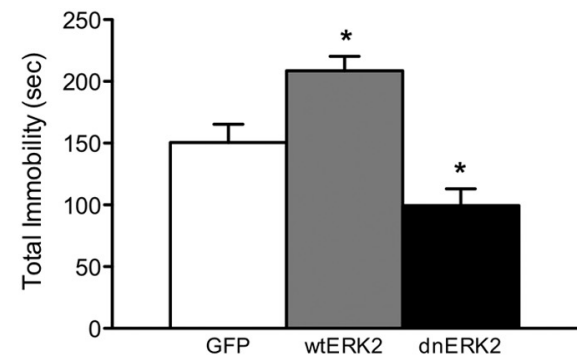

Figure 3. ERK2 in the VTA regulates behavior responses in the rat forced swim test and the mouse tail suspension test. In the forced swim test, latencies to become immobile varied as a function of viral vector treatment ( $n=12-13$ per group). Latency to becomeimmobile was significantly decreased in rats treated with HSV-wtERK2 and significantly increased in rats treated with HSV - dnERK2 when compared with HSV-GFP controls ( $\left.{ }^{*} p<0.05\right)$. $\boldsymbol{a}$, Total immobility was also influenced by viral treatment with HSV-dnERK2-treated rats showing significantly lower total immobility. $\boldsymbol{b}$, Behavioral counts were affected by viral treatment. HSV-dnERK2-treated rats showed fewer floating $(p<0.05)$ and greater climbing $(p<0.05)$ and swimming $\left(V_{p}=0.07\right)$ counts compared with HSV-GFP controls. There were no group differences when locomotor activity (distance traveled in centimeter), rather than swimming, was quantified during testing day ( $\boldsymbol{b}$, inset; $n=4$ per group). $\boldsymbol{c}$, Viral infusions into the substantia nigra (anatomical control; $n=5$ per group) did not influence latency to immobility or total immobility in the rat forced swim test. $\boldsymbol{d}$, In mice, HSV-wtERK2 increased, whereas HSV-dnERK2 decreased, total immobility in the tail suspension test ( $n=6$ per group) when compared with HSV-GFP controls. Data are presented as latencies to become immobile and total immobility (in seconds) and as cumulative 5 s intervals of swimming, climbing, and floating counts (mean \pm SEM). FST, Forced swim test.

present, $\left.t_{(12)}=3.19, p<0.001\right)$, thus indicating increased vulnerability to stress under these conditions. Assessing time in the corner zones (Fig. 4e), which provides an additional measure of social avoidance (Krishnan et al., 2007), yielded similar results: wtERK2-treated mice spent significantly more time in the corners in the presence of the aggressor (target absent vs target present, $\left.t_{(14)}=2.61, p<0.02\right)$ or when compared with the HSVGFP-treated controls $\left(t_{(12)}=2.98, p<0.01\right)$.

In a separate experiment, naive $\mathrm{C} 57 \mathrm{BL} / 6$ mice were subjected to a full $10 \mathrm{~d}$ of social defeat (Fig. 4c), which induces social avoidance in the majority of animals (Krishnan et al., 2007), an effect that can be reversed by chronic, but not acute, antidepressant treatment (Berton et al., 2006; Tsankova et al., 2006). Only those defeated mice demonstrating significantly high levels of social avoidance were selected to receive microinjections of HSV-GFP $(n=6)$ or HSV-dnERK2 $(n=7)$ into the VTA. No differences in the magnitude of social avoidance were detected between these groups before surgery (data not shown). Three days after viral infusions (Fig. 4f), HSV-GFP-treated mice showed the expected decrease in interaction times in response to a CD1 mouse $\left(t_{(10)}=2.8, p<0.01\right)$. Conversely, the HSVdnERK2-treated mice did not display social avoidance in the presence of the aggressor $(p>0.05)$, and, on the contrary, they displayed a tendency toward social interaction $(p=0.06)$, thus showing that decreasing ERK2 in the VTA ameliorates the effects of chronic social defeat stress. This was further evidenced when assessing the time spent in the corner zones (Fig. $4 g$ ), because the
GFP-treated mice spent significantly more time in the corners when compared with HSV-dnERK2-treated mice $\left(t_{(11)}=2.32\right.$, $p<0.05)$.

ERK2 modulates preference for sucrose To further characterize the functional consequences of altered ERK2 signaling within the rat VTA, we assessed the effects of wtERK2 and dnERK2 on behavioral reactivity to a natural reward, namely, sucrose preference (Fig. $5 a-d)(n=12-15$ per group). This procedure has been used extensively as an animal model of anhedonia (Willner et al., 1987; Papp et al., 1991; Sampson et al., 1992). Overall analyses indicated that HSV microinjections did not significantly affect the total fluid intake (water + sucrose) during either testing day (Fig. $5 b)$. However, sucrose preference varied as a function of ERK2 expression $\left(F_{(2,38)}=\right.$ $14.45, p<0.003)$. HSV-wtERK2 overexpression increased sucrose preference when compared with its pretest scores (Fig. $5 a$ ) or the HSV-GFP-treated rats during the posttesting day $(p<0.05)$.

ERK2 activity within the VTA also regulated preference for sucrose after $7 \mathrm{~d}$ of chronic unpredictable stress. Viral-mediated gene transfer influenced sucrose preference as a function of virus treatment $\left(F_{(3,68)}=7.76, p<0.0001\right)$, stress (before vs after stress, $F_{(1,68)}=$ $12.67, p<0.001)$ and virus $\times$ stress interaction $\left(F_{(3,68)}=10.84, p<0.0001\right)$ without affecting total liquid intake $(n=8-10$ per group, $p>0.05$ ) (Fig. $5 d$ ). Post hoc analyses show that chronic unpredictable stress alone decreased sucrose preference (a depression-like effect) in the sham- and GFP-treated rats ( $p<0.05$, before vs after stress, respectively) (Fig. $5 c$ ). Conversely, we found that wtERK2 overexpression enhanced preference for sucrose after chronic unpredictable stress when compared with sham- and HSV-GFP-treated rats $(p<$ 0.05 , respectively). Downregulation of ERK2 did not affect sucrose preference after chronic stress, thus indicating that HSVdnERK2 blocked the effects of chronic unpredictable stress on sucrose preference (Fig. 5c), an antidepressant-like effect (Willner et al., 1987).

\section{ERK2 activity in the VTA regulates responses to}

nociceptive stimuli

We next assessed the influence of ERK2 in the rat VTA on unconditioned behavioral responses to nociceptive stimuli $(n=10-11$ per group) (Fig. 6a). When compared with the GFP-treated group, overexpression of wtERK2 in the VTA decreased the threshold footshock intensity required to elicit jumping $\left(F_{(2,29)}=\right.$ 23.08, $p<0.001$ ), without affecting the threshold intensity to elicit a flinch reaction. A similar pattern of results was observed for the intensity necessary to evoke vocalization $\left(F_{(2,29)}=5.68\right.$, $p<0.01)$, with wtERK2-treated rats showing lower threshold intensity when compared with the dnERK2-treated group $(p<$ $0.05)$, but not the GFP-treated control group ( $p>0.05)$. No differences between controls and dnERK2-treated rats were observed. 


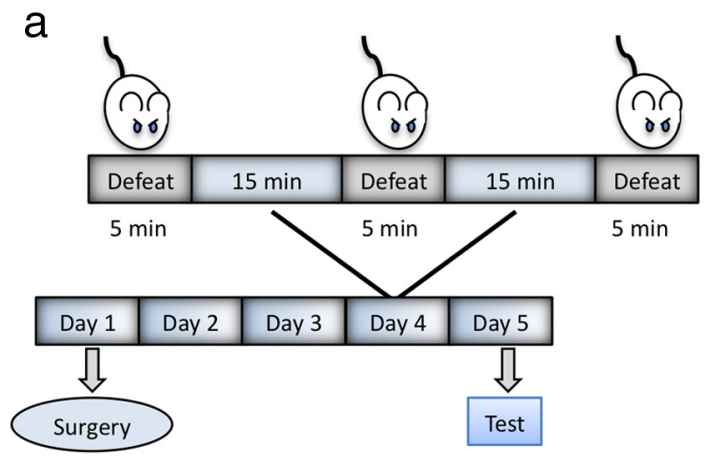

b

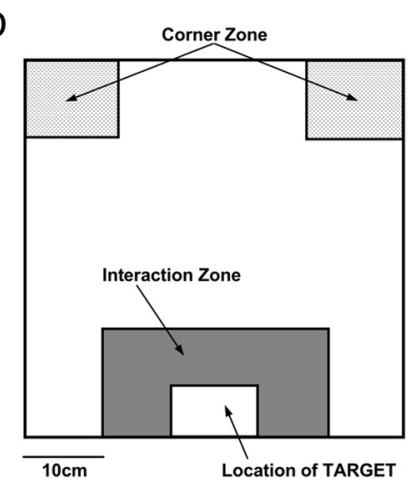

C

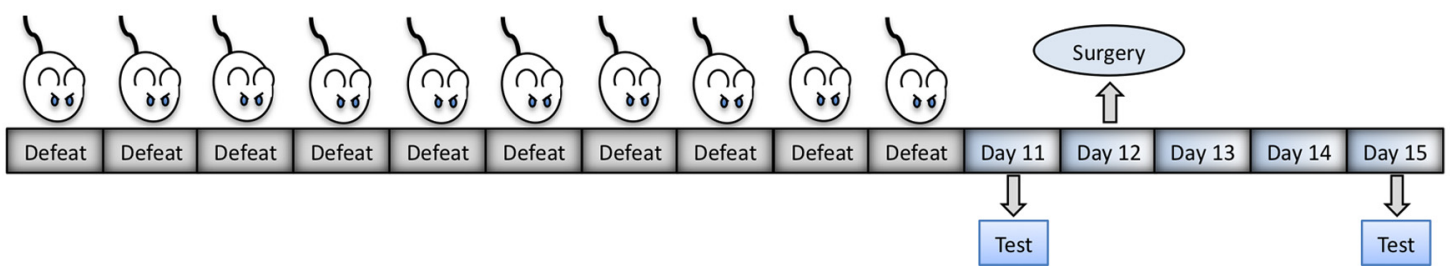

Submaximal Defeat d

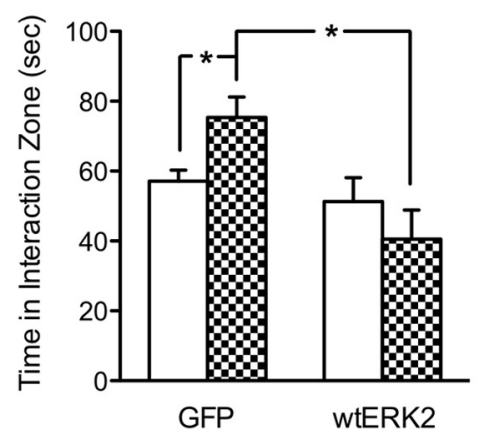

e

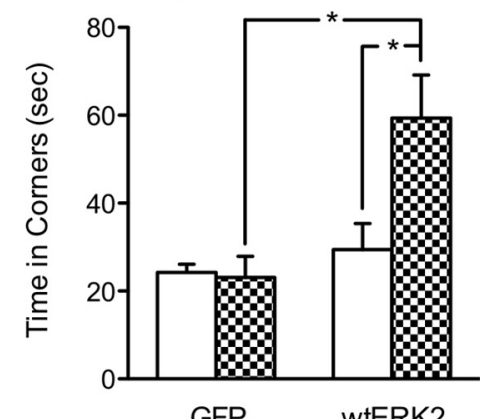

Chronic Defeat f

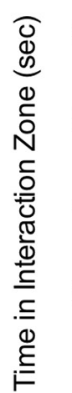

$\mathrm{g}$

Target Absent Target Present

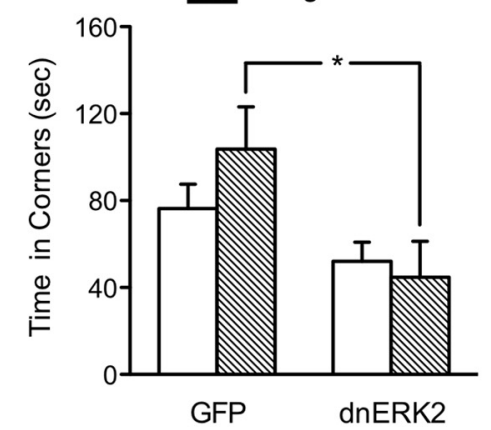

Figure 4. ERK2 in the VTA regulates behavior responses in the social defeat procedure in C57BL/6 mice. $\boldsymbol{a}$, Schematic timeline of the submaximal social defeat procedure, in which C57BL/6 mice were defeated three times within a single day, $3 \mathrm{~d}$ after HSV-GFP or HSV-wtERK2 infusions into the VTA. $\boldsymbol{b}$, Schematic diagram of the social interaction/avoidance arena illustrating the geographic location and size of the interaction and corner zones with respect to the enclosure in which a social target is positioned. $c$, Schematic timeline of the chronic social defeat procedure, in which 5 57BL/6 mice were defeated 10 consecutive days (10 min/episode). Mice showing clear avoidance phenotypes $24 \mathrm{~h}$ after the last defeat (day 11) underwent HSV (GFP or dnERK2) surgery on day 12 and were tested for social avoidance behaviors on day 15 ( $3 \mathrm{~d}$ after HSV surgery). $\boldsymbol{d}$, Naive mice infused with HSV-GFP $(n=6)$ and subjected to submaximal social defeat showed significantly higher levels of interaction $(p<0.05)$, whereas HSV-wtERK2 overexpression in the VTA $(n=8)$ prevented interaction levels ( $p>0.05$; HSV-wtERK2 target absent vs target present). Furthermore, HSV-wtERK2-treated mice showed significantly less time in the interaction zone when compared with HSV-GFP-treated mice $(p<0.05)$ in the presence of the target. $\boldsymbol{e}$, This was also evident when assessing time in the corner zones, in which HSV-wtERK2-treated mice spent significantly more time in the corners in the presence of the target. In the chronic social defeat experiment, we examined the effects of viral manipulation on two matched groups of socially avoidant mice $(n=6-7$ per group). $f$, Whereas a clear avoidant phenotype was observed after an intra-VTA injection of HSV-GFP $(p<0.05)$, overexpression of HSV-dnERK2 alleviated social avoidance $(p>0.05)$ and showed higher social interaction $(\vee p=0.06)$. $g$, When assessing time in the corner zone, HSV-GFPtreated mice spent significantly more time in the corners when compared with HSV-dnERK2-treated mice. Data are presented as mean \pm SEM. ${ }^{*} p<0.05$.

ERK2 activity in the VTA regulates anxiety-like behavior

The effects of ERK2 activity within the VTA on anxiety-eliciting situations, as measured by the elevated plus maze, are shown in Figure $6 b(n=13$ per group). A one-way ANOVA revealed that percentage time spent in the open arms varied as a function of virus treatment $\left(F_{(2,36)}=10.42, p<0.001\right)$. HSV-wtERK2treated rats spent significantly less time in the open arms (an anxiety-like response) when compared with HSV-GFP controls $(p<0.05)$, whereas HSV-dnERK2-treated rats did not differ from the HSV-GFP-treated controls $(p>0.05)$. Virus treatment also affected the percentage of entries into the open arms of the maze $\left(F_{(2,36)}=7.73, p<0.002\right)$. No differences in the percentage of entries into the open arms were observed between the HSVdnERK2-treated and HSV-GFP-treated rats $(p>0.05)$, whereas
HSV-wtERK2-treated rats had a tendency toward less percentage entries onto the open arms compared with the HSV-GFP-treated controls $(p=0.057)$. Additionally, virus treatment influenced time spent self-grooming in the closed arms of the maze $\left(F_{(2,36)}=\right.$ $10.72, p<0.001)$. Although the HSV-wtERK2-treated rats displayed higher $(p=0.055)$ and the dnERK2-treated rats displayed lower ( $p=0.052$ ) self-grooming (when compared with the HSV-GFP-treated rats), these differences were marginally significant.

\section{ERK2 regulation of VTA dopamine neuron firing rate}

Our behavioral data indicate that overexpression of HSVwtERK2 in the VTA increases susceptibility to stress, whereas overexpression of HSV-dnERK2 produces stress-resistant re- 

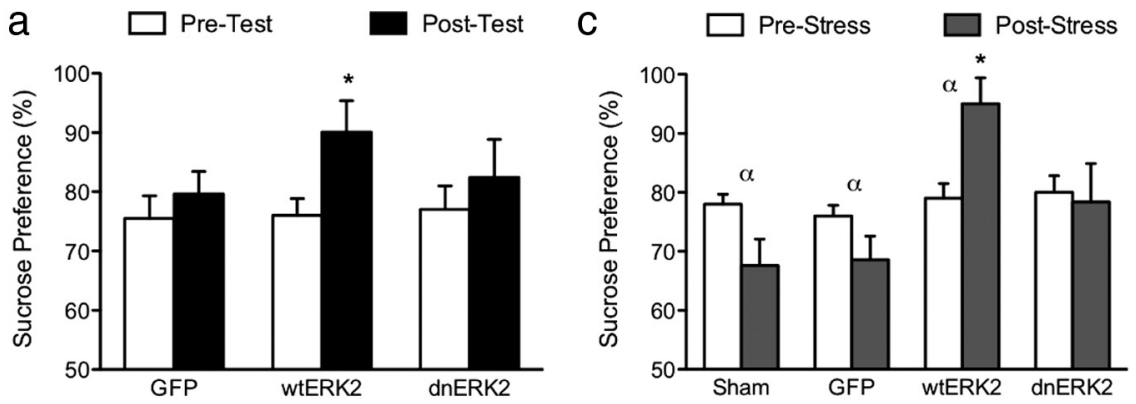

b

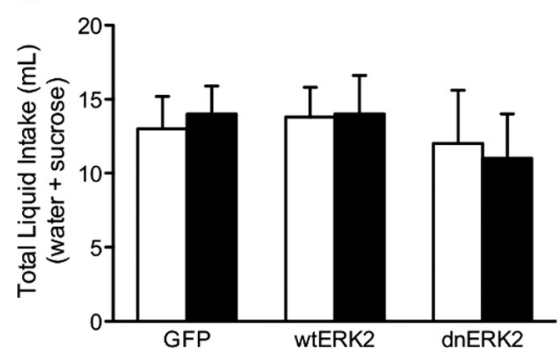

d

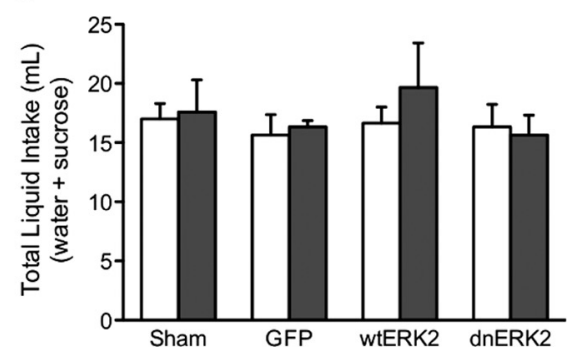

Figure 5. ERK2 in the VTA regulates sucrose preference. $\boldsymbol{a}, \boldsymbol{b}, 0$ verexpression of ERK2 (HSV-wtERK2) in the VTA of normal rats increased sucrose preference $(\boldsymbol{a})$, without affecting total liquid (water + sucrose) intake $(\boldsymbol{b})$. Data are presented as percentage difference of total liquid intake (water + sucrose) between presucrose and postsucrose test ( $n=12-15$ per group). ERK2 activity in the VTA also regulates responses to sucrose preference after 1 week of chronic unpredictable stress $(\boldsymbol{c}, \boldsymbol{d} ; n=8-10$ per group). Stress alone significantly decreased sucrose intake in sham (non-viral-treated) and HSV-GFP-treated rats. $\boldsymbol{c}, \boldsymbol{d}$, HSV-wtERK2 overexpression increased sucrose preference above levels seen in sham and HSV-GFP controls (c), without affecting total liquid intake (d). HSV-dnERK2 prevented the decrease in sucrose preference after chronic unpredictable stress (c). ${ }^{\alpha}$ Significantly different between before and after stress. ${ }^{*} p<0.05$ between sham- and HSV-GFP-treated groups.

sponses in several assays. Recently, we found that resistance to chronic social defeat stress is causally related to decreased firing of VTA dopamine neurons (Krishnan et al., 2007, 2008). Based on these observations, we determined whether altered ERK2 activity modulates the firing rate of these neurons (Fig. $7 a-c$ ). Extracellular recordings of rat VTA dopamine neurons $(n=22-24$ per group) in slice cultures of brain showed that their firing rate was influenced by virus treatment $\left(F_{(3,86)}=3.08, p<0.05\right)$. Consistent with our behavioral data, we found that HSV-dnERK2 significantly lowered the firing rate of VTA dopamine neurons when compared with non-virus-treated (GFP-) or HSVGFP-infected $(\mathrm{GFP}+)$ VTA slices $(p<0.05)$ (Fig. 7c). However, no differences in firing rate were observed between any of the other groups $(p>0.05)$.

\section{Discussion}

The present study was designed to assess whether acute or chronic exposure to stress alters the ERK pathway within the VTA and, if so, whether such adaptations influence an animal's behavioral reactivity to stress and other mood-eliciting stimuli. This approach was taken because the mesolimbic dopamine reward pathway is important in the regulation of mood and motivation under normal conditions and in behavioral abnormalities seen in depression and other mood disorders (Fibiger and Phillips, 1981; Willner, 1983; Anisman and Zacharko, 1986; Wise and Bozarth, 1987; Koob, 1996; Naranjo et al., 2001; Nestler and Carlezon, 2006; Yadid and Friedman, 2008). Although the mechanisms underlying these effects continue to be explored, several reports have implicated brain-derived neurotrophic factor (BDNF) in the behavioral and cellular adaptations that occur in the VTA after exposure to stress (Eisch et al., 2003; Berton et al., 2006; Krishnan et al., 2007), and ERK is one of the key signaling mole- cules downstream of BDNF (Huang and Reichardt, 2003). We show here that acute or chronic exposure to stress increases ERK1/2 activity in the VTA and that selectively increasing ERK2 activity within the VTA enhances sensitivity to stressful situations, whereas blockade of ERK2 activity in this brain region exerts behavioral responses similar to those observed after administration of antidepressants (Cryan et al., 2002; Krishnan and Nestler, 2008; Iñiguez et al., 2010).

Two major isoforms of ERK, ERK1 and ERK2, are expressed in the VTA and other brain areas. These isoforms may have distinct functions in brain (Lloyd, 2006), but the specific role that each plays is not understood, because the two isoforms are very similar in sequence (Yoon and Seger, 2006) and the pharmacological tools currently available cannot distinguish between them (Nishimoto and Nishida, 2006). Genetic inactivation of ERK1 results in animals displaying basal locomotor alterations (Selcher et al., 2001) with compensations of enhanced ERK2 signaling in the brain (Ferguson et al., 2006), thus making behavioral interpretation of these mutants difficult. ERK2 deletions result in early embryonic lethality (Aouadi et al., 2006). We therefore took advantage of viral-mediated gene transfer, which makes it possible to assess the functional effects induced by modulation of ERK2 activity selectively within the VTA of adult animals on functional responses in several overlapping behavioral tests that assess mood in rodents.

Our findings with viral-mediated gene transfer demonstrate a clear behavioral phenotype caused by manipulating ERK2 activity within the VTA. Increasing ERK2 activity in this region increased susceptibility to stress. Animals treated with HSV-wtERK2 exhibited decreased latency to immobility and decreased escape-like behaviors in the rat forced swim test and displayed greater total immobility in the mouse tail suspension test, effects opposite to those elicited by antidepressant treatments (Porsolt et al., 1977; Cryan et al., 2002, 2005). The decreased latency to immobility observed in the HSV-wtERK2-treated rats did not result from deficits in motor activity because these rats did not show alterations in basal locomotion (Fig. $3 b$, inset). Increased susceptibility to stress induced by HSV-wtERK2 was further supported by our findings in the social defeat procedure. Mice expressing HSVwtERK2 in the VTA displayed social avoidance in response to submaximal defeat episodes, a behavioral response opposite to control mice, which displayed higher social interaction under these conditions (Krishnan et al., 2007, 2008). Additional experiments also revealed increased reactivity to anxiogenic stimuli during activation of ERK2 in the VTA in that HSV-wtERK2treated rats spent significantly less time in the open arms of the elevated plus maze and more time engaged in grooming behavior, a typical behavior in response to stressful or anxiogenic stimuli (Spruijt et al., 1988; Bolaños et al., 2003a), and displayed increased sensitivity to nociceptive stimuli. Conversely, decreasing ERK2 activity in the VTA, achieved by overexpressing HSVdnERK2, induced potent stress-resistant effects in the forced 
swim test, tail suspension test, and chronic social defeat procedure. HSV-dnERK2 also reversed a decrease in sucrose preference induced by $7 \mathrm{~d}$ of chronic unpredictable stress, a response categorized as antidepressant-like behavior (Willner et al., 1987; Pucilowski et al., 1993; Di Chiara et al., 1999; Tacchi et al., 2008). In contrast, HSV-dnERK2 did not affect responses to nociceptive or anxiogenic stimuli. Together, these data demonstrate that stress-induced activation of ERK2 within the VTA is both necessary and sufficient to mediate depression-like sequelae of stress, with a possible role in anxiogenic and aversive sequelae as well.

Surprisingly, we also found that elevated ERK2 activity in the VTA enhances sucrose preference, in both normal and stressed animals, a finding that appears contradictory to a depressive-like response seen in several other assays. The explanation for this paradoxical effect remains unknown. One possibility is that wtERK2 overexpression in this brain region sensitizes the reward circuitry despite inducing depression-like behavior (Yap and Miczek, 2008), thus mimicking enhanced responses to appetitive behaviors observed in rodents after stress (Lu et al., 2006; Lin et al., 2010). Chronic stress has been found to both decrease (Zacharko et al., 1983) and increase (Willner et al., 1998; Kreibich et al., 2009) appetitive responses, and therefore the enhanced sucrose preference induced by wtERK2 could represent a specific characteristic of a subtype of depressive disorder (Kosten et al., 1998; Posternak, 2003; Nestler and Carlezon, 2006). Clearly, additional research is needed to delineate the role played by ERK in the VTA in the interactions between responses to natural reward and stress.

Previous work indicates that the dopamine system is highly responsive to stress (Horger and Roth, 1996) because both fear and restraint stress increases dopamine neuron firing rate (Guarraci and Kapp, 1999; Anstrom and Woodward, 2005), and enhanced excitability of these neurons is a signature of susceptibility to social defeat stress (Krishnan et al., 2007, 2008). We therefore assessed the effects of HSV-ERK2 treatments on VTA firing rates using a VTA slice culture preparation. We discovered that HSVdnERK2 treatment significantly decreased the firing rate of VTA dopamine neurons, consistent with the antidepressant-like effects of this manipulation demonstrated here in several behavioral assays, whereas no change in firing rate was evident after HSV-wtERK2 treatment. A possible mechanism by which decreased ERK2 activity reduces VTA firing rate is via $\mathrm{GABA}_{\mathrm{A}}$ receptors, because pharmacological inhibition of ERK results in an enhancement of $\mathrm{GABA}_{\mathrm{A}}$-gated currents in heterologous expression systems (Bell-Horner et al., 2006). Given the present behavioral results, it is surprising that HSV-wtERK2 did not increase VTA firing rate. It is conceivable that increased ERK2 activity does not increase dopamine cell firing per se but may enhance the intrinsic excitability of neurons such that the cells are primed to respond excessively in response to stress, a possibility that now requires additional in vivo investigation. As well, the viral vectors used in the present study, although specific for neurons, target all neurons; thus, it would be important in future studies to determine which class of VTA neurons (i.e., dopaminergic vs GABAergic) are responsible for mediating the observed ERK2-induced biochemical and behavioral responses.

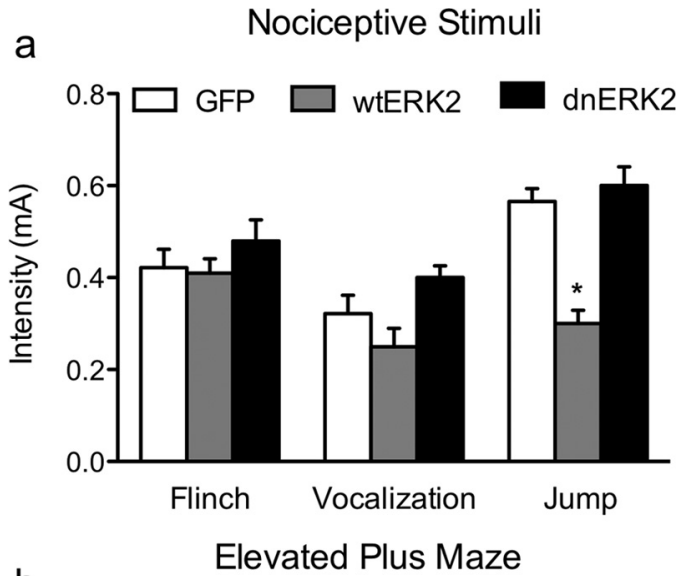

b

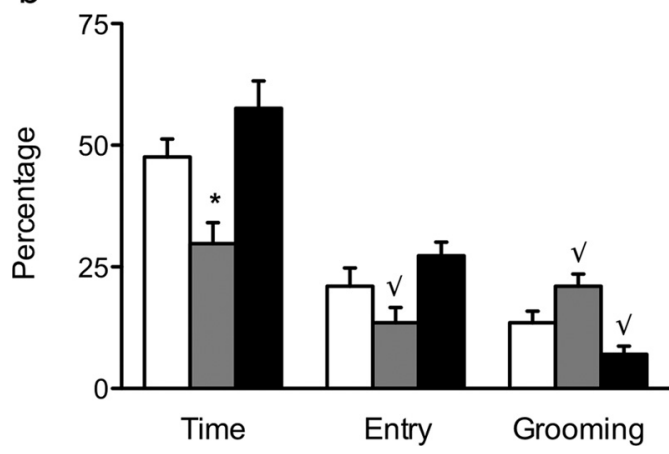

Figure 6. $\boldsymbol{a}, \boldsymbol{b}$, ERK2 in the ventral tegmental area regulates responses to nociceptive $(\boldsymbol{a})$ and anxiogenic $(\boldsymbol{b})$ stimuli. Rats with HSV-wtERK2 overexpression jumped at lower footshock intensities than rats overexpressing GFP ( $n=10-11$ per group). HSV-GFP-and HSV-dnERK2-treated rats did not differ in their responses to footshock. $\boldsymbol{b}$, Rats overexpressing wtERK2 spent significantly less time in the open arms of the elevated plus maze than the HSV-GFP controls ( $n=13$ per group). HSVwtERK2-treated rats also had a tendency toward less open arm entries and higher grooming time within the closed arms compared with HSV-GFP-treated rats. ${ }^{*} p<0.05$, significantly different from HSV-GFP group. $V_{p}=0.05$ when compared with HSV-GFP controls. a
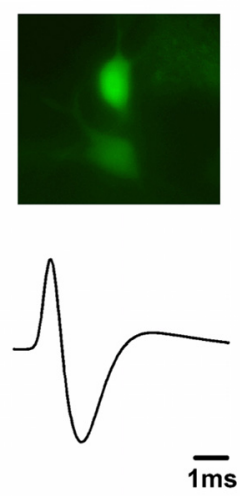

b
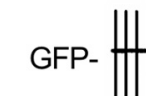

$$
\text { GFP+ }
$$

wtERK2

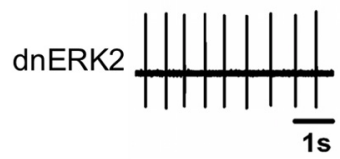

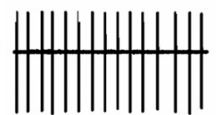

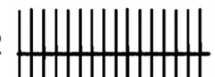

C

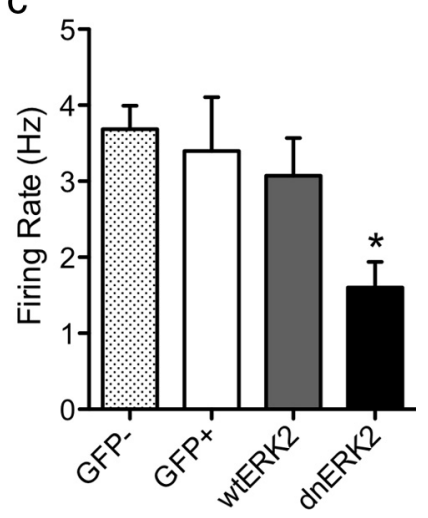

Figure 7. Decreased ERK2 lowers the excitability of VTA dopamine neurons ( $n=22-24$ cells per group). $\boldsymbol{a}$, GFP expression of infected dopaminergic neurons within the VTA slice culture and a sample spontaneous triphasic waveform action potential. $\boldsymbol{b}$, Sample recordings from untreated (GFP-), HSV-GFP-treated (GFP +), HSV-wtERK2-GFP-treated (wtERK2), and HSVdnERK2-GFP-treated (dnERK2) VTA slice cultures. c, HSV-dnERK2-infected VTA neurons showed a significantly decreased firing rate when compared with controls (GFP - and GFP + ). ${ }^{*} p<0.05$.

Previous studies assessing the role of ERK activity in mediating responses to stress and antidepressant-like effects are equivocal. Pharmacological inhibition of ERK activity in hippocampus, amygdala, or prefrontal cortex has been reported to induce a pro-depressant behavioral response (Duman et al., 2007; Gourley 
et al., 2008; Tronson et al., 2008; Qi et al., 2009), whereas others report antidepressant phenotypes (Fumagalli et al., 2005; Huang and Lin, 2006; Creson et al., 2009; Todorovic et al., 2009). The discrepancies between these studies may be the result of experimental design factors, such as stress conditions, antidepressant exposure (i.e., regimen and dose), and differential effects of various pharmacological inhibitors on several cellular elements (neuronal cell bodies, nerve terminals, and glia) within the injected area. In contrast, HSV vectors affect neuronal cell bodies only and thereby enable more precise hypotheses to be tested. Regardless, the observation that manipulations of the ERK pathway in different brain regions bring about distinct behavioral phenotypes in response to stress is not surprising, because BDNF, which is upstream of ERK, induces opposite behaviors between the hippocampus (Shirayama et al., 2002; Duman and Monteggia, 2006) and the VTA-NAc circuitry (Eisch et al., 2003; Berton et al., 2006; Krishnan et al., 2007).

Our overall findings are in agreement with abundant evidence suggesting that the ERK pathway plays an important role in mediating several domains of complex behavior, including responses to drugs of abuse (Berhow et al., 1996; Lu et al., 2006; Girault et al., 2007; Lu et al., 2009) and mood regulation (Manji et al., 2000; Einat et al., 2003; Dwivedi et al., 2006; Todorovic et al., 2009). More specifically, we establish a novel role for elevated ERK2 levels within the VTA in increasing sensitivity to stressful circumstances, whereas blockade of ERK2 activity in this region results in a stress-resistant phenotype. Thus, our data identify a new neurobiological mechanism underlying stress responsiveness and point directly to ERK2 and its many downstream signaling molecules as potential therapeutic targets for mood disorders (Manji and Chen, 2002). The present results further substantiate the influence of the VTA-NAc circuit on mood regulation and underscore the need for a clearer understanding of the mechanisms downstream of ERK2 in the VTA that regulate depressionlike behavior.

\section{References}

Alonso M, Vianna MR, Izquierdo I, Medina JH (2002) Signaling mechanisms mediating BDNF modulation of memory formation in vivo in the hippocampus. Cell Mol Neurobiol 22:663-674.

Anisman H, Zacharko RM (1986) Behavioral and neurochemical consequences associated with stressors. Ann NY Acad Sci 467:205-225.

Anstrom KK, Woodward DJ (2005) Restraint increases dopaminergic burst firing in awake rats. Neuropsychopharmacology 30:1832-1840.

Aouadi M, Binetruy B, Caron L, Le Marchand-Brustel Y, Bost F (2006) Role of MAPKs in development and differentiation: lessons from knockout mice. Biochimie 88:1091-1098.

Barrot M, Olivier JD, Perrotti LI, DiLeone RJ, Berton O, Eisch AJ, Impey S, Storm DR, Neve RL, Yin JC, Zachariou V, Nestler EJ (2002) CREB activity in the nucleus accumbens shell controls gating of behavioral responses to emotional stimuli. Proc Natl Acad Sci U S A 99:11435-11440.

Bell-Horner CL, Dohi A, Nguyen Q, Dillon GH, Singh M (2006) ERK/ MAPK pathway regulates GABAA receptors. J Neurobiol 66:1467-1474.

Berhow MT, Hiroi N, Nestler EJ (1996) Regulation of ERK (extracellular signal regulated kinase), part of the neurotrophin signal transduction cascade, in the rat mesolimbic dopamine system by chronic exposure to morphine or cocaine. J Neurosci 16:4707-4715.

Bertolucci-D'Angio M, Serrano A, Driscoll P, Scatton B (1990) Involvement of mesocorticolimbic dopaminergic systems in emotional states. Prog Brain Res 85:405-416; discussion 416-417.

Berton O, McClung CA, Dileone RJ, Krishnan V, Renthal W, Russo SJ, Graham D, Tsankova NM, Bolanos CA, Rios M, Monteggia LM, Self DW, Nestler EJ (2006) Essential role of BDNF in the mesolimbic dopamine pathway in social defeat stress. Science 311:864-868.

Bolaños CA, Nestler EJ (2004) Neurotrophic mechanisms in drug addiction. Neuromolecular Med 5:69-83.

Bolaños CA, Barrot M, Berton O, Wallace-Black D, Nestler EJ (2003a)
Methylphenidate treatment during pre- and periadolescence alters behavioral responses to emotional stimuli at adulthood. Biol Psychiatry 54:1317-1329.

Bolaños CA, Perrotti LI, Edwards S, Eisch AJ, Barrot M, Olson VG, Russell DS, Neve RL, Nestler EJ (2003b) Phospholipase C $\gamma$ in distinct regions of the ventral tegmental area differentially modulates mood-related behaviors. J Neurosci 23:7569-7576.

Bonnet KA, Peterson KE (1975) A modification of the jump-flinch technique for measuring pain sensitivity in rats. Pharmacol Biochem Behav 3:47-55.

Carlezon WA Jr, Boundy VA, Haile CN, Lane SB, Kalb RG, Neve RL, Nestler EJ (1997) Sensitization to morphine induced by viral-mediated gene transfer. Science 277:812-814.

Carlezon WA Jr, Thome J, Olson VG, Lane-Ladd SB, Brodkin ES, Hiroi N, Duman RS, Neve RL, Nestler EJ (1998) Regulation of cocaine reward by CREB. Science 282:2272-2275.

Conner JM, Lauterborn JC, Yan Q, Gall CM, Varon S (1997) Distribution of brain-derived neurotrophic factor (BDNF) protein and mRNA in the normal adult rat CNS: evidence for anterograde axonal transport. J Neurosci 17:2295-2313.

Council NR (2003) Guideliness for the care and use of mammals in neuroscience and behavioral research. Washington, DC: National Academy.

Covington HE 3rd, Miczek KA (2005) Intense cocaine self-administration after episodic social defeat stress, but not after aggressive behavior: dissociation from corticosterone activation. Psychopharmacology (Berl) 183:331-340.

Creson TK, Hao Y, Engel S, Shen Y, Hamidi A, Zhuo M, Manji HK, Chen G (2009) The anterior cingulate ERK pathway contributes to regulation of behavioral excitement and hedonic activity. Bipolar Disord 11:339-350.

Cryan JF, Markou A, Lucki I (2002) Assessing antidepressant activity in rodents: recent developments and future needs. Trends Pharmacol Sci 23:238-245.

Cryan JF, Mombereau C, Vassout A (2005) The tail suspension test as a model for assessing antidepressant activity: review of pharmacological and genetic studies in mice. Neurosci Biobehav Rev 29:571-625.

Detke MJ, Lucki I (1996) Detection of serotonergic and noradrenergic antidepressants in the rat forced swimming test: the effects of water depth. Behav Brain Res 73:43-46.

Di Chiara G, Loddo P, Tanda G (1999) Reciprocal changes in prefrontal and limbic dopamine responsiveness to aversive and rewarding stimuli after chronic mild stress: implications for the psychobiology of depression. Biol Psychiatry 46:1624-1633.

Duman CH, Schlesinger L, Kodama M, Russell DS, Duman RS (2007) A role for MAP kinase signaling in behavioral models of depression and antidepressant treatment. Biol Psychiatry 61:661-670.

Duman RS, Monteggia LM (2006) A neurotrophic model for stress-related mood disorders. Biol Psychiatry 59:1116-1127.

Dwivedi Y, Rizavi HS, Conley RR, Pandey GN (2006) ERK MAP kinase signaling in post-mortem brain of suicide subjects: differential regulation of upstream Raf kinases Raf-1 and B-Raf. Mol Psychiatry 11:86-98.

Einat H, Yuan P, Gould TD, Li J, Du J, Zhang L, Manji HK, Chen G (2003) The role of the extracellular signal-regulated kinase signaling pathway in mood modulation. J Neurosci 23:7311-7316.

Eisch AJ, Bolaños CA, de Wit J, Simonak RD, Pudiak CM, Barrot M, Verhaagen J, Nestler EJ (2003) Brain-derived neurotrophic factor in the ventral midbrain-nucleus accumbens pathway: a role in depression. Biol Psychiatry 54:994-1005.

Ferguson SM, Fasano S, Yang P, Brambilla R, Robinson TE (2006) Knockout of ERK1 enhances cocaine-evoked immediate early gene expression and behavioral plasticity. Neuropsychopharmacology 31:2660-2668.

Fibiger HC, Phillips AG (1981) Increased intracranial self-stimulation in rats after long-term administration of desipramine. Science 214:683-685.

Fitzgerald LW, Ortiz J, Hamedani AG, Nestler EJ (1996) Drugs of abuse and stress increase the expression of GluR1 and NMDAR1 glutamate receptor subunits in the rat ventral tegmental area: common adaptations among cross-sensitizing agents. J Neurosci 16:274-282.

Fumagalli F, Molteni R, Calabrese F, Frasca A, Racagni G, Riva MA (2005) Chronic fluoxetine administration inhibits extracellular signal-regulated kinase 1/2 phosphorylation in rat brain. J Neurochem 93:1551-1560.

Girault JA, Valjent E, Caboche J, Hervé D (2007) ERK2: a logical AND gate critical for drug-induced plasticity? Curr Opin Pharmacol 7:77-85.

Gourley SL, Wu FJ, Kiraly DD, Ploski JE, Kedves AT, Duman RS, Taylor JR 
(2008) Regionally specific regulation of ERK MAP kinase in a model of antidepressant-sensitive chronic depression. Biol Psychiatry 63:353-359.

Graham DL, Krishnan V, Larson EB, Graham A, Edwards S, Bachtell RK, Simmons D, Gent LM, Berton O, Bolanos CA, DiLeone RJ, Parada LF, Nestler EJ, Self DW (2009) Tropomyosin-related kinase B in the mesolimbic dopamine system: region-specific effects on cocaine reward. Biol Psychiatry 65:696-701.

Guarraci FA, Kapp BS (1999) An electrophysiological characterization of ventral tegmental area dopaminergic neurons during differential pavlovian fear conditioning in the awake rabbit. Behav Brain Res 99:169-179.

Han MH, Bolaños CA, Green TA, Olson VG, Neve RL, Liu RJ, Aghajanian GK, Nestler EJ (2006) Role of cAMP response element-binding protein in the rat locus ceruleus: regulation of neuronal activity and opiate withdrawal behaviors. J Neurosci 26:4624-4629.

Hetman M, Gozdz A (2004) Role of extracellular signal regulated kinases 1 and 2 in neuronal survival. Eur J Biochem 271:2050-2055.

Horger BA, Roth RH (1996) The role of mesoprefrontal dopamine neurons in stress. Crit Rev Neurobiol 10:395-418.

Horger BA, Iyasere CA, Berhow MT, Messer CJ, Nestler EJ, Taylor JR (1999) Enhancement of locomotor activity and conditioned reward to cocaine by brain-derived neurotrophic factor. J Neurosci 19:4110-4122.

Huang EJ, Reichardt LF (2003) Trk receptors: roles in neuronal signal transduction. Annu Rev Biochem 72:609-642.

Huang TY, Lin CH (2006) Role of amygdala MAPK activation on immobility behavior of forced swim rats. Behav Brain Res 173:104-111.

Iñiguez SD, Warren BL, Neve RL, Nestler EJ, Russo SJ, Bolaños-Guzmán CA (2008) Insulin receptor substrate-2 in the ventral tegmental area regulates behavioral responses to cocaine. Behav Neurosci 122:1172-1177.

Iñiguez SD, Warren BL, Parise EM, Alcantara LF, Schuh B, Maffeo ML, Manojlovic Z, Bolaños-Guzmán CA (2009) Nicotine exposure during adolescence induces a depression-like state in adulthood. Neuropsychopharmacology 34:1609-1624.

Iñiguez SD, Warren BL, Bolaños-Guzmán CA (2010) Short- and long-term functional consequences of fluoxetine exposure during adolescence in male rats. Biol Psychiatry 67:1057-1066.

Jensen J, McIntosh AR, Crawley AP, Mikulis DJ, Remington G, Kapur S (2003) Direct activation of the ventral striatum in anticipation of aversive stimuli. Neuron 40:1251-1257.

Kelley AE, Berridge KC (2002) The neuroscience of natural rewards: relevance to addictive drugs. J Neurosci 22:3306-3311.

Koob GF (1996) Hedonic valence, dopamine and motivation. Mol Psychiatry 1:186-189.

Koob GF, Le Moal M (2001) Drug addiction, dysregulation of reward, and allostasis. Neuropsychopharmacology 24:97-129.

Kosten TR, Markou A, Koob GF (1998) Depression and stimulant dependence: neurobiology and pharmacotherapy. J Nerv Ment Dis 186:737-745.

Kreibich AS, Briand L, Cleck JN, Ecke L, Rice KC, Blendy JA (2009) Stressinduced potentiation of cocaine reward: a role for CRF R1 and CREB. Neuropsychopharmacology 34:2609-2617.

Krishnan V, Nestler EJ (2008) The molecular neurobiology of depression. Nature 455:894-902.

Krishnan V, Han MH, Graham DL, Berton O, Renthal W, Russo SJ, Laplant Q, Graham A, Lutter M, Lagace DC, Ghose S, Reister R, Tannous P, Green TA, Neve RL, Chakravarty S, Kumar A, Eisch AJ, Self DW, Lee FS, Tamminga CA, Cooper DC, Gershenfeld HK, Nestler EJ (2007) Molecular adaptations underlying susceptibility and resistance to social defeat in brain reward regions. Cell 131:391-404.

Krishnan V, Han MH, Mazei-Robison M, Iñiguez SD, Ables JL, Vialou V, Berton O, Ghose S, Covington HE 3rd, Wiley MD, Henderson RP, Neve RL, Eisch AJ, Tamminga CA, Russo SJ, Bolaños CA, Nestler EJ (2008) AKT signaling within the ventral tegmental area regulates cellular and behavioral responses to stressful stimuli. Biol Psychiatry 64:691-700.

Lin X, Wang Q, Ji J, Yu LC (2010) Role of MEK-ERK pathway in morphineinduced conditioned place preference in ventral tegmental area of rats. J Neurosci Res 88:1595-1604.

Lloyd AC (2006) Distinct functions for ERKs? J Biol 5:13.

Lu L, Dempsey J, Liu SY, Bossert JM, Shaham Y (2004) A single infusion of brain-derived neurotrophic factor into the ventral tegmental area induces long-lasting potentiation of cocaine seeking after withdrawal. J Neurosci 24:1604-1611.
Lu L, Koya E, Zhai H, Hope BT, Shaham Y (2006) Role of ERK in cocaine addiction. Trends Neurosci 29:695-703.

Lu L, Wang X, Wu P, Xu C, Zhao M, Morales M, Harvey BK, Hoffer BJ, Shaham Y (2009) Role of ventral tegmental area glial cell line-derived neurotrophic factor in incubation of cocaine craving. Biol Psychiatry 66:137-145.

Lucki I (1997) The forced swimming test as a model for core and component behavioral effects of antidepressant drugs. Behav Pharmacol 8:523-532.

Manji HK, Chen G (2002) PKC, MAP kinases and the bcl-2 family of proteins as long-term targets for mood stabilizers. Mol Psychiatry 7 [Suppl $1]: S 46-S 56$.

Manji HK, Moore GJ, Chen G (2000) Clinical and preclinical evidence for the neurotrophic effects of mood stabilizers: implications for the pathophysiology and treatment of manic-depressive illness. Biol Psychiatry 48:740-754.

Montgomery KC (1955) The relation between fear induced by novel stimulation and exploratory behavior. J Comp Physiol Psychol 48:254-260.

Naranjo CA, Tremblay LK, Busto UE (2001) The role of the brain reward system in depression. Prog Neuropsychopharmacol Biol Psychiatry 25:781-823.

Nestler EJ, Carlezon WA Jr (2006) The mesolimbic dopamine reward circuit in depression. Biol Psychiatry 59:1151-1159.

Nestler EJ, Berhow MT, Brodkin ES (1996) Molecular mechanisms of drug addiction: adaptations in signal transduction pathways. Mol Psychiatry 1:190-199.

Nestler EJ, Barrot M, DiLeone RJ, Eisch AJ, Gold SJ, Monteggia LM (2002) Neurobiology of depression. Neuron 34:13-25.

Neve RL, Howe JR, Hong S, Kalb RG (1997) Introduction of the glutamate receptor subunit 1 into motor neurons in vitro and in vivo using a recombinant herpes simplex virus. Neuroscience 79:435-447.

Nishimoto S, Nishida E (2006) MAPK signalling: ERK5 versus ERK1/2. EMBO Rep 7:782-786.

Numan S, Seroogy KB (1999) Expression of trkB and trkC mRNAs by adult midbrain dopamine neurons: a double-label in situ hybridization study. J Comp Neurol 403:295-308.

Olson VG, Zabetian CP, Bolanos CA, Edwards S, Barrot M, Eisch AJ, Hughes T, Self DW, Neve RL, Nestler EJ (2005) Regulation of drug reward by cAMP response element-binding protein: evidence for two functionally distinct subregions of the ventral tegmental area. J Neurosci 25:5553-5562.

Ortiz J, Harris HW, Guitart X, Terwilliger RZ, Haycock JW, Nestler EJ (1995) Extracellular signal-regulated protein kinases (ERKs) and ERK kinase (MEK) in brain: regional distribution and regulation by chronic morphine. J Neurosci 15:1285-1297.

Ortiz J, Fitzgerald LW, Lane S, Terwilliger R, Nestler EJ (1996) Biochemical adaptations in the mesolimbic dopamine system in response to repeated stress. Neuropsychopharmacology 14:443-452.

Papp M, Willner P, Muscat R (1991) An animal model of anhedonia: attenuation of sucrose consumption and place preference conditioning by chronic unpredictable mild stress. Psychopharmacology (Berl) 104:255-259.

Paxinos G, Watson C (1997) The rat brain in stereotaxic coordinates, Ed 3. San Diego: Academic.

Perrotti LI, Hadeishi Y, Ulery PG, Barrot M, Monteggia L, Duman RS, Nestler EJ (2004) Induction of deltaFosB in reward-related brain structures after chronic stress. J Neurosci 24:10594-10602.

Pierce RC, Bari AA (2001) The role of neurotrophic factors in psychostimulantinduced behavioral and neuronal plasticity. Rev Neurosci 12:95-110.

Pliakas AM, Carlson RR, Neve RL, Konradi C, Nestler EJ, Carlezon WA Jr (2001) Altered responsiveness to cocaine and increased immobility in the forced swim test associated with elevated cAMP response elementbinding protein expression in nucleus accumbens. J Neurosci 21:7397-7403.

Poo MM (2001) Neurotrophins as synaptic modulators. Nat Rev Neurosci 2:24-32.

Porsolt RD, Le Pichon M, Jalfre M (1977) Depression: a new animal model sensitive to antidepressant treatments. Nature 266:730-732.

Porsolt RD, Chermat R, Lenègre A, Avril I, Janvier S, Stéru L (1987) Use of the automated tail suspension test for the primary screening of psychotropic agents. Arch Int Pharmacodyn Ther 288:11-30. 
Posternak MA (2003) Biological markers of atypical depression. Harv Rev Psychiatry 11:1-7.

Pucilowski O, Overstreet DH, Rezvani AH, Janowsky DS (1993) Chronic mild stress-induced anhedonia: greater effect in a genetic rat model of depression. Physiol Behav 54:1215-1220.

Qi X, Lin W, Wang D, Pan Y, Wang W, Sun M (2009) A role for the extracellular signal-regulated kinase signal pathway in depressive-like behavior. Behav Brain Res 199:203-209.

Rattiner LM, Davis M, Ressler KJ (2005) Brain-derived neurotrophic factor in amygdala-dependent learning. Neuroscientist 11:323-333.

Robinson MJ, Harkins PC, Zhang J, Baer R, Haycock JW, Cobb MH, Goldsmith EJ (1996) Mutation of position 52 in ERK2 creates a nonproductive binding mode for adenosine 5' -triphosphate. Biochemistry 35:5641-5646.

Russo SJ, Bolanos CA, Theobald DE, DeCarolis NA, Renthal W, Kumar A, Winstanley CA, Renthal NE, Wiley MD, Self DW, Russell DS, Neve RL, Eisch AJ, Nestler EJ (2007) IRS2-Akt pathway in midbrain dopamine neurons regulates behavioral and cellular responses to opiates. Nat Neurosci 10:93-99.

Russo-Neustadt AA, Beard RC, Huang YM, Cotman CW (2000) Physical activity and antidepressant treatment potentiate the expression of specific brain-derived neurotrophic factor transcripts in the rat hippocampus. Neuroscience 101:305-312.

Saal D, Dong Y, Bonci A, Malenka RC (2003) Drugs of abuse and stress trigger a common synaptic adaptation in dopamine neurons. Neuron 37:577-582.

Sampson D, Muscat R, Phillips G, Willner P (1992) Decreased reactivity to sweetness following chronic exposure to mild unpredictable stress or acute administration of pimozide. Neurosci Biobehav Rev 16:519-524.

Schmidt HD, Duman RS (2007) The role of neurotrophic factors in adult hippocampal neurogenesis, antidepressant treatments and animal models of depressive-like behavior. Behav Pharmacol 18:391-418.

Schoenbaum G, Stalnaker TA, Shaham Y (2007) A role for BDNF in cocaine reward and relapse. Nat Neurosci 10:935-936.

Schuman EM (1999) Neurotrophin regulation of synaptic transmission. Curr Opin Neurobiol 9:105-109.

Selcher JC, Nekrasova T, Paylor R, Landreth GE, Sweatt JD (2001) Mice lacking the ERK1 isoform of MAP kinase are unimpaired in emotional learning. Learn Mem 8:11-19.

Shaham Y, Erb S, Stewart J (2000) Stress-induced relapse to heroin and cocaine seeking in rats: a review. Brain Res Brain Res Rev 33:13-33.

Shirayama Y, Chen AC, Nakagawa S, Russell DS, Duman RS (2002) Brainderived neurotrophic factor produces antidepressant effects in behavioral models of depression. J Neurosci 22:3251-3261.

Spruijt BM, Welbergen P, Brakkee J, Gispen WH (1988) An ethological analysis of excessive grooming in young and aged rats. Ann NY Acad Sci 525:89-100.

Steru L, Chermat R, Thierry B, Simon P (1985) The tail suspension test: a new method for screening antidepressants in mice. Psychopharmacology (Berl) 85:367-370.

Subramaniam S, Unsicker K (2010) ERK and cell death: ERK1/2 in neuronal death. FEBS J 277:22-29.

Tacchi R, Ferrari A, Loche A, Bertolini A (2008) Sucrose intake: increase in non-stressed rats and reduction in chronically stressed rats are both prevented by the gamma-hydroxybutyrate (GHB) analogue, GET73. Pharmacol Res 57:464-468.

Todorovic C, Sherrin T, Pitts M, Hippel C, Rayner M, Spiess J (2009) Suppression of the MEK/ERK signaling pathway reverses depression-like behaviors of CRF2-deficient mice. Neuropsychopharmacology 34:1416-1426.

Tronson NC, Schrick C, Fischer A, Sananbenesi F, Pagès G, Pouysségur J, Radulovic J (2008) Regulatory mechanisms of fear extinction and depression-like behavior. Neuropsychopharmacology 33:1570-1583.

Tsankova NM, Berton O, Renthal W, Kumar A, Neve RL, Nestler EJ (2006) Sustained hippocampal chromatin regulation in a mouse model of depression and antidepressant action. Nat Neurosci 9:519-525.

Ungless MA, Magill PJ, Bolam JP (2004) Uniform inhibition of dopamine neurons in the ventral tegmental area by aversive stimuli. Science 303:2040-2042.

Werkman TR, Olijslagers JE, Perlstein B, Jansen AH, McCreary AC, Kruse CG, Wadman WJ (2004) Quetiapine increases the firing rate of rat substantia nigra and ventral tegmental area dopamine neurons in vitro. Eur J Pharmacol 506:47-53.

Wiley MD, Poveromo LB, Antapasis J, Herrera CM, Bolaños Guzmán CA (2009) Kappa-opioid system regulates the long-lasting behavioral adaptations induced by early-life exposure to methylphenidate. Neuropsychopharmacology 34:1339-1350.

Willner P (1983) Dopamine and depression: a review of recent evidence. I. Empirical studies. Brain Res 287:211-224.

Willner P, Towell A, Sampson D, Sophokleous S, Muscat R (1987) Reduction of sucrose preference by chronic unpredictable mild stress, and its restoration by a tricyclic antidepressant. Psychopharmacology (Berl) 93:358-364.

Willner P, Benton D, Brown E, Cheeta S, Davies G, Morgan J, Morgan M (1998) "Depression" increases "craving" for sweet rewards in animal and human models of depression and craving. Psychopharmacology (Berl) 136:272-283.

Wise RA (1987) The role of reward pathways in the development of drug dependence. Pharmacol Ther 35:227-263.

Wise RA (2004) Dopamine, learning and motivation. Nat Rev Neurosci 5:483-494.

Wise RA, Bozarth MA (1987) A psychomotor stimulant theory of addiction. Psychol Rev 94:469-492.

Yadid G, Friedman A (2008) Dynamics of the dopaminergic system as a key component to the understanding of depression. Prog Brain Res 172:265-286.

Yan Q, Radeke MJ, Matheson CR, Talvenheimo J, Welcher AA, Feinstein SC (1997) Immunocytochemical localization of TrkB in the central nervous system of the adult rat. J Comp Neurol 378:135-157.

Yap JJ, Miczek KA (2008) Stress and rodent models of drug addiction: role of VTA-accumbens-PFC-amygdala circuit. Drug Discov Today Dis Models 5:259-270.

Yoon S, Seger R (2006) The extracellular signal-regulated kinase: multiple substrates regulate diverse cellular functions. Growth Factors 24:21-44.

Zacharko RM, Bowers WJ, Kokkinidis L, Anisman H (1983) Regionspecific reductions of intracranial self-stimulation after uncontrollable stress: possible effects on reward processes. Behav Brain Res 9:129-141. 